\title{
Análise da produção científica sobre gênero na Educação Física brasileira entre os anos de 2013 e 2018: uma perspectiva Cientométrica
} Analysis of scientific production on gender in Brazilian Physical Education between 2013 and 2018: a Scientometry perspective

\section{Análisis de la producción científica sobre género en la Educação Física brasileña entre 2013 y 2018: una perspectiva Cientométrica}

\author{
Jéssica de Moura Pereira ${ }^{a}$ (D) , Dulce Maria Filgueira de Almeida ${ }^{b}$ (D), Raquel da Silveira ${ }^{c}$
}

Palavras-chave:

Gênero;

Educação Física;

Produção científica;

Cientometria.

Keywords:

Gender;

Physical Education;

Scientific production; Scientometry.

Palabras clave:

Género;

Educación Física;

Producción científica;

Cientometría.

\begin{abstract}
RESUMO
O artigo analisa a produção científica sobre gênero no campo de conhecimento e intervenção pedagógica da EF no Brasil. A pesquisa foi composta de uma fase exploratória-descritiva centrada na Cientometria. O corpus de análise foi constituído por 20 dissertações e teses defendidas entre os anos de 2013 e 2018. Evidenciam-se como resultados: a produção está concentrada nas regiões sudeste e sul do país; os principais programas são PPGEF/UFMG e PPGCMH/UFRGS; as temáticas estudadas se direcionam à questão das mulheres e esporte; e as mulheres despontam como autoras. Por fim, destacamos que as produções parecem refletir demandas políticas e sociais acerca da categoria gênero, o que pode ser inferido devido ao acréscimo da produção e efervescência de pautas antigênero a partir de 2013.
\end{abstract}

\begin{abstract}
The paper analyzes the scientific production on gender in the Physical Education, field of knowledge and pedagogical intervention, in Brazil. The research consisted of an exploratorydescriptive phase centered on Scientometry. The analysis corpus consisted of 20 dissertations and theses defended between the years 2013 and 2018. The results show us: the production is concentrated in the southeastern and southern regions of the country; the main programs are PPGEF/UFMG and PPGCMH/UFRGS; the themes studied are directed to the issue of women and sport; and women emerge as authors. We show that the production seems to reflect the political and social demands regarding the gender category, which can be inferred according to the increase in production and effervescence of antigender agendas from 2013.
\end{abstract}

\section{RESUMEN}

El artículo analiza la producción científica sobre género en el campo del conocimiento y de la intervención pedagógica de la EF en Brasil. La investigación consistió en una fase exploratoriadescriptiva centrada en la Cienciometría. El corpus de análisis estuvo conformado por 20 disertaciones y tesis defendidas entre los años 2013 y 2018. Los resultados son: la producción se concentra en las regiones sureste y sur; los programas principales son PPGEF/UFMG y PPGCMH/UFRGS; los estudios están dirigidos al tema de mujeres y deporte; y las mujeres emergen como autoras. Mostramos que las producciones parecen reflejar las demandas políticas y sociales en torno a la categoría de género, lo que se puede inferir de acuerdo con el incremento en la producción y efervescencia de agendas anti-género a partir de 2013.

aUniversidade Estadual de Goiás, Escola Superior de Educação Física e Fisioterapia de Goiás. Goiânia, GO, Brasil.

'Universidade de Brasília, Faculdade de Educação Física, Programa de Pós-graduação em Educação Física, Núcleo de Estudos do Corpo e Natureza. Brasília, DF, Brasil.

'Universidade Federal do Rio Grande do Sul, Programa de Pós-graduação em Ciências do Movimento Humano da Escola Superior de Educação Física. Porto Alegre, RS, Brasil.

\footnotetext{
*Autor correspondente:

Jéssica de Moura Pereira

E-mail: jessica.pereira@ueg.br
} 


\section{INTRODUÇÃO}

Vaitsman (1994, p. 8) argumenta que "na gênese do indivíduo moderno não houve espaço para que a diferença entre os sexos se expressasse de forma igualitária, traduzindo-se, ao contrário, por meio de uma dicotomia e uma hierarquia de gênero entre homens "universal» e mulheres "outro»", o que garantiu que os princípios de autonomia e igualdade se conformassem como "atributos do gênero masculino".

Com o esporte moderno (e incluímos aqui a EF) não foi diferente, pois, sendo considerado um fenômeno de totalidade social peles ${ }^{1}$ historiadores das décadas de 1970 e 1980, e caracterizando ainda "a expressão da cultura do mundo científico", como proposto por Guttman (1978 apud Booth, 2011, p. 4), "foi/é um dos principais espaços para a construção, expressão e conservação do modelo tradicional de masculinidade", tal como reiteraram Dunning e Maguire (1997, p.322).

A anexação dos estudos de gênero e feministas às agendas de pesquisas brasileiras no campo das Ciências Sociais e Humanas é audaciosa, apresentando certas particularidades no que se refere à predileção pelo uso de determinados vocábulos, o que é decorrente do impacto exercido pelas correntes de pensamento francesa e anglófona. A título de exemplo, em França, a teoria materialista do feminismo, de inspiração marxista, usa o termo «relações sociais de sexo" como equivalente à "construção social do sexo» que, consequentemente, corresponde a gênero, um termo atual, poderíamos dizer, que na qualidade de conceito é "utilizado com maior frequência, inclusive no Brasil", devido aos resultados da influência do pós-estruturalismo na crítica e produção acadêmico-científica feminista do fim do século XX (Scavone, 2009).

Com base nestas acepções constatamos que dissertar sobre a temática de gênero exige de nós, consoante ao exposto por Scavone (2009, p. 11), a capacidade de percorrermos "todas as análises, posições teóricas e políticas divergentes que são parte do pensamento feminista crítico, quais sejam: igualdade

1 Consideraremos, na escrita deste artigo, a tentativa de inclusão do gênero não-binário como "alternativa para a usual generalização no masculino". Não optaremos pelo emprego de @ ou x, mas sim pelo “e”, iles e/ou diles para que pessoas cegas tenham o texto integralmente lido pelos aplicativos de acessibilidade. Recorremos ao Manifesto ile para uma comunicação radicalmente inclusiva, por entender que nossas vidas e a língua portuguesa não são estáticas, podendo assim se adaptar para que novas realidades sejam retratadas. "O próprio estranhamento que a palavra diles causar nos ouvidos das pessoas já será parte da mudança". Disponível em: https://diversitybbox.com/pt/manifesto-ile-para-umacomunicacao-radicalmente-inclusiva/. Acesso em: 15 set. 2020. e/ou diferença, universal e/ou particular, sexo e/ou gênero. Penetrar neste espaço é, pois, estabelecer contato com o substrato político feminista", observando, assim, uma pluralidade de conhecimentos.

Destarte, ainda que as questões políticas estejam implícitas em relação às produções científicas, nos propomos a divulgar parte desses pensamentos a fim de que sejam alargadas as possibilidades de visibilizá-los. Esclarecer condutas que precisam ser renovadas e que repercutem nos círculos sociais, políticos e acadêmicos é um meio de assegurar que as interpretações da realidade extrapolarão o senso comum e estarão resguardadas por algum senso crítico (Hirata et al., 2009).

O presente artigo tem o propósito de analisar as dissertações e teses sobre gênero na área de conhecimento e intervenção pedagógica da EF. Adicionalmente, acreditamos que a mensuração destas produções compreende um dos desafios de nossa pesquisa, haja vista que buscamos explorar "o grande terreno subterrâneo dos saberes subjugados", como definiu Haraway (1995, p. 23), e almejamos ter a oportunidade de contribuir com pesquisas futuras num campo que também é reconhecido por suas "múltiplas ontologias científicas", como propõe Raquel da Silveira (2016).

Um conjunto de inquietações fizeram parte de nossa curiosidade científica sobre o tema, como por exemplo: nacionalmente, onde está localizada a produção sobre gênero? Quais são os PPGs e quais docentes orientaram essas pesquisas? Que temáticas são mais suscitadas peles pesquisadores? Para responder essas questões, nos empenhamos na (1) identificação das instituições e agentes que viabilizam as pesquisas sobre gênero na $E F$ e; (2) na assimilação das características dessas investigações e de quem as protagonizam.

Um pressuposto é que as informações aqui apresentadas podem repercutir em inferências importantes para outres pesquisadores e demonstrar a relevância de incorporar os Estudos de Gênero à EF, basta ver que as produções atendem a certa regularidade mesmo não estando adequadamente distribuídas pelo território nacional.

\section{MATERIAL E MÉTODOS}

Essa é uma pesquisa bibliográfica sendo o corpus de análise constituído por dissertações e teses defendidas em PPGs da EF entre os anos de 2013 e 2018, lapso temporal que coincidiu com a criação do GTT Gênero no CBCE em 2013 - período em que a produção se torna cada vez mais extensa e dispõe de maior legitimidade no cenário científico - e, em 2018, com a intensificação dos discursos antigênero que fizeram ascender à presidência do Brasil o candidato das pautas de morte.

As produções foram mapeadas nos repositórios: Biblioteca Digital de Teses e Dissertações (BDTD) e Catálogo de Teses e Dissertações da CAPES. A escolha desses sítios resultou da constatação de uma desatualização referente 
aos endereços eletrônicos e acervos de alguns dos PPGs da área, como no caso do PPGEF/UnB ${ }^{2}$, e ainda, pela dificuldade encontrada em determinar um padrão de busca para recuperar os textos e viabilizar a replicação deste estudo. Cabe frisar que algumas produções não puderam ser contabilizadas pelo fato de pertencerem a outras áreas do conhecimento.

Para o cumprimento dos objetivos deste artigo nós compreendemos como exequível a combinação entre argumentações de naturezas quanti e qualitativa. Bauer e Gaskell (2008, p. 22-23) destacam que pesquisas qualitativas lidam com "a interpretação das realidades sociais" e buscam apresentar possibilidades de antecipar "futuras trajetórias" do objeto investigado, enquanto as quantitativas envolvem "números e uso de modelos estatísticos", baseando-se na mensuração dos dados de uma amostra que, embora abstratos, são igualmente analisáveis.

Ademais, a pesquisa foi composta de uma fase exploratória-descritiva cuja abordagem é a Cientometria, um método quantitativo pautado na mensuração de informações acerca da pesquisa científica. Segundo Tague-Sutcliffe (1992 apud Maricato e Noronha, 2012, p. 23), tal procedimento constitui "o estudo dos aspectos quantitativos da ciência enquanto uma disciplina ou atividade econômica. Faz parte da sociologia da ciência, com aplicações voltadas ao desenvolvimento de políticas científicas", distinguindo-se da Bibliometria.

Um dos critérios estabelecidos para chegarmos à amostra de 20 produções considerou que as defesas ocorreram necessariamente em PPGs brasileiros da EF. Ao todo foram reunidas 17 obras de mestrado e 3 de doutorado, das quais: 13 dissertações no formato monográfico, 1 dissertação e 1 tese em estilo escandinavo, em buscas realizadas na BDTD; e 3 dissertações e 2 teses através do Catálogo de Teses e Dissertações. Deste total, em algumas das etapas, apenas 18 produções foram avaliadas, pois que se encontravam em formato monográfico ${ }^{3}$.

Quanto ao processo analítico mais amplo, destacamos a utilização do software IRAMUTEQ, criado pelo Laboratoire d'Études et de Recherches Appliquées en Sciences Sociales da Universidade de Toulouse, que viabiliza análises estatísticas de materiais textuais, entretanto, as publicizaremos em outro artigo.

\footnotetext{
$2 \mathrm{Na}$ altura do mapeamento das produções, uma tese de doutorado havia sido defendida no PPGEF/UnB, mas não constava no acervo. A corporeidade no ciberespaço: estilo de vida, dor, sacrifício e feminilidades das mulheres na cultura do músculo (2018) por Valleria A. de Oliveira sob a orientação da Profa. Dra. Dulce M. F. de Almeida.

3 Para algumas análises foram excluídas as dissertações e teses apresentadas no estilo escandinavo em razão da dificuldade de enquadramento em uma categoria temática por gozarem de pouca homogeneidade.
}

\section{RESULTADOS E DISCUSSÃO}

\section{INSTITUIÇÕES E AGENTES QUE POSSIBILI- TARAM A PRODUÇÃO CIENTÍFICA SOBRE GÊNERO NA EF BRASILEIRA}

A interação entre pesquisadores e pares; ou pesquisadores e sociedade, bem como a disseminação e entendimento sobre a necessidade de certos temas serem pautados, podem, a prioristicamente, potencializar o enfrentamento a problemas sociais tão graves quanto os que vivenciamos. Neste sentido, encontramos em determinados estudos/teorias/epistemologias um direcionamento para que nossas pesquisas possam restituir a comunidade acadêmica e a sociedade, apresentando alguma relevância.

Neste sentido, quando propomos localizar a produção científica geograficamente, percebendo assim sua vinculação com os PPGs; ou sabermos quais docentes orientam e as linhas de pesquisa que integram, inclusive, conseguindo apresentar o crescimento quantitativo de instituições e agentes ao longo do tempo, temos em vista, pretensiosamente, informar à comunidade acadêmicocientífica sobre o possível impacto dos Estudos de Gênero nas pesquisas da EF.

Com efeito, o primeiro dado a ser considerado é a localização geográfica da produção científica e sua vinculação aos PPGs. As informações que trazemos abaixo (Gráfico 1) nos permitem identificar o número de dissertações e teses sobre gênero produzidas no contexto da EF no período de 2013-2018, conforme o mapeamento das regiões brasileiras:

Consoante os dados expostos acima, temos o seguinte: dentre as 20 produções, 10 foram defendidas na região Sul, das quais: 8 dissertações e 2 teses; 9 na região Sudeste, das quais: 8 dissertações e 1 tese; e por fim, 1 dissertação na região Nordeste. Essa distribuição ao longo do território nacional expressa o que Sidone et al. (2016, p. 17) identificaram, uma vez que "a configuração espacial da atividade científica é distribuída de maneira bastante desigual, tanto entre países como internamente aos territórios nacionais, sendo que no Brasil o padrão regional da distribuição das publicações e dos pesquisadores é altamente concentrado no Sudeste, com destaque às capitais dos estados".

Sidone et al. (2016) apontam ainda que os esforços cooperativos entre pesquisadores dentro de um país, são fatores que impactam positivamente no aumento e na descentralização das produções, mas, logicamente, não podemos desconsiderar a distribuição desproporcional dos incentivos e auxílios financeiros que chegam a determinadas regiões, universidades e/ou grupos de pesquisa, etc.

O segundo aspecto analisado diz respeito à proporcionalidade entre as orientações e docentes que orientaram durante o período investigado (2013-2018). 

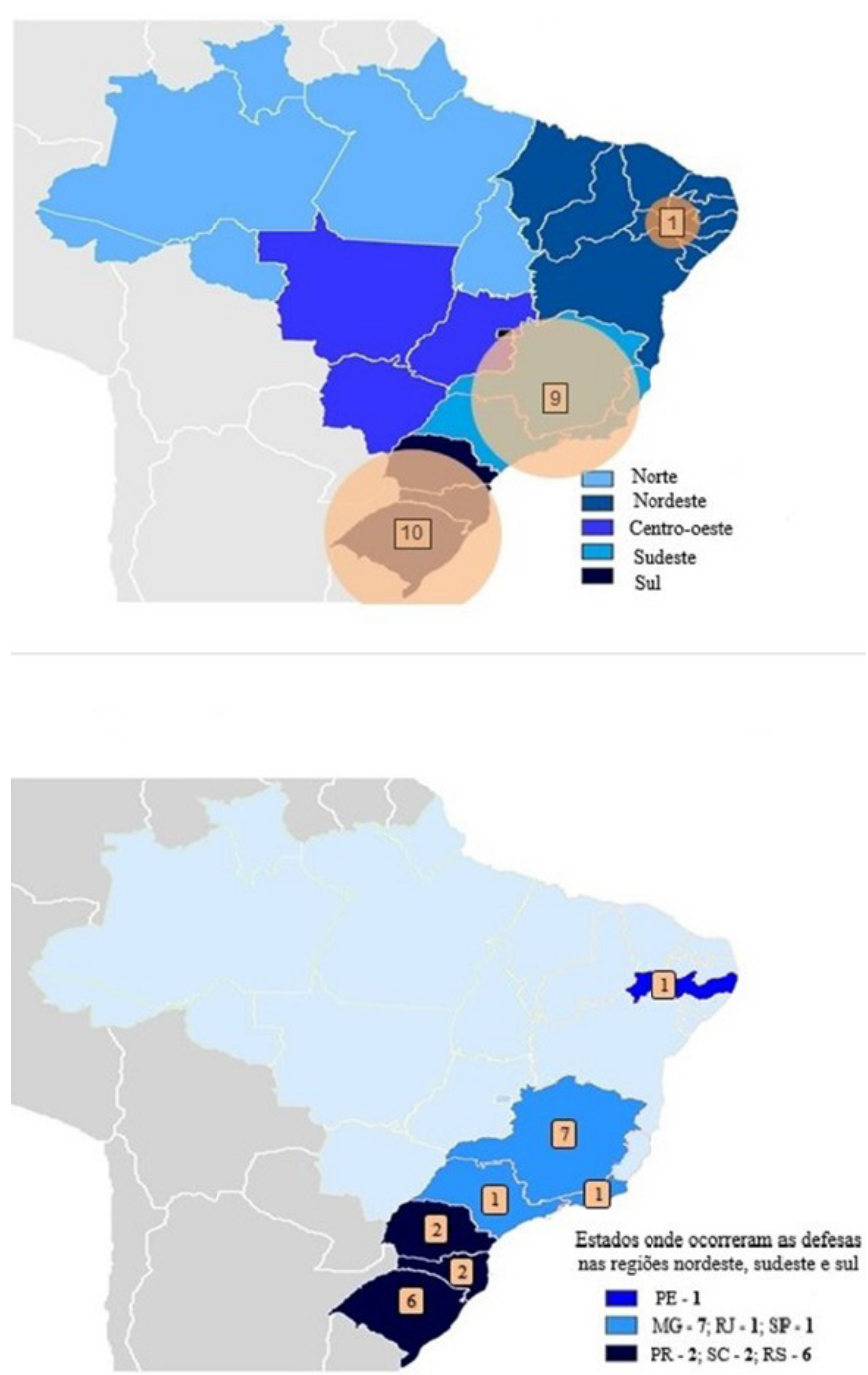

Gráfico 1. Concentração das dissertações e/ou teses de acordo com as regiões e os estados do Brasil em que foram defendidas entre os anos de 2013 a 2018. Fonte: elaboração própria (2020).

No Gráfico 2 apresentamos os dados considerando-se os PPGs:

Verifica-se que há uma preponderância na orientação das dissertações e teses por parte das professoras Ludmila Mourão (PPGEF/MG) e Silvana Goellner (PPGCMH/RS). Adicionalmente, vale mencionar que as professoras citadas, além de representarem os maiores números em termos de orientações envolvendo a temática de gênero, compartilham de referenciais teórico-metodológicos e participam de modo concomitante das mesmas bancas, o que não denota uma simples coincidência.

Ficou evidente a ocorrência de intenso diálogo e troca de experiências entre ambas, fator que oportuniza a ampliação desses conhecimentos na área da EF. Um aspecto a destacar é que esse tráfego que aparenta ser 'via de mão dupla', mantém-se entre as regiões sudeste e sul, precisamente entre Minas Gerais e o Rio Grande do Sul, o que sinaliza que mais intercâmbios precisam ser constituídos.

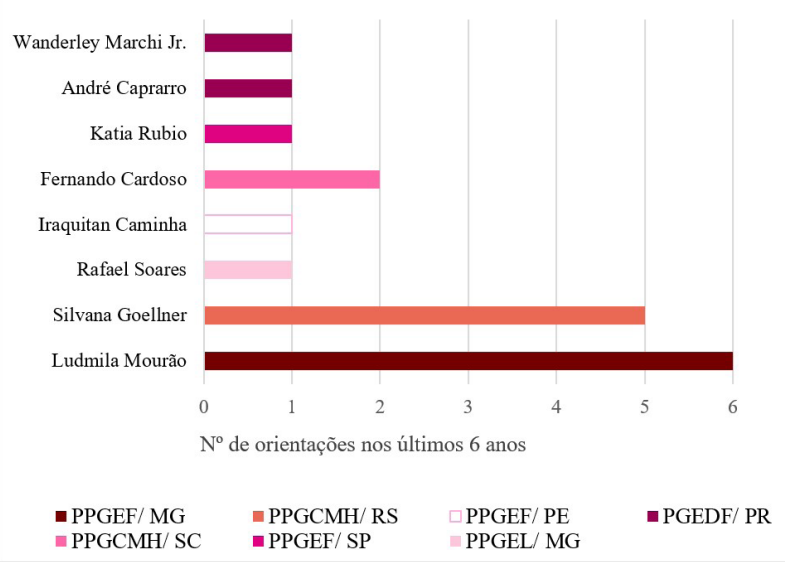

Gráfico 2. Proporção de orientações por orientadore entre os anos de 2013 e 2018 considerando-se os PPGs. Fonte: elaboração própria (2019).

Em meio à hegemonia sudestina-sulista, na região nordeste, recuperamos a dissertação intitulada Esporte e heteronormatividade: preconceitos encontrados/ enfrentados por homossexuais de Jarlson Silva sob a orientação de Iraquitan Caminha, docente credenciado ao Programa Associado de Pós-Graduação em EF das Universidade do Estado de Pernambuco/Universidade Federal da Paraíba.

Partindo dessas informações é imprescindível que direcionemos nossos esforços para criar, nacionalmente, laços de apoio científico amplamente dedicados à sistematização, consolidação e, principalmente, complexificação dos conhecimentos oriundos dos Estudos de Gênero no contexto da EF. Na Figura 1 conseguimos ter a dimensão da distribuição de orientandes e produção com relação às docentes:

Conforme os dados apresentados acima, é possível perceber a distribuição das orientações para cada orientadore. Nos seis anos analisados, Ludmila Mourão do PPGEF/UFJF-UFV, orientou 7 pós-graduandes, seguida por Silvana Goellner do PPGCMH/UFRGS, que no mesmo período orientou 5 pós-graduandes.

A Profa. Dra. Ludmila Mourão é líder do grupo de pesquisa Gênero, Educação Física, Saúde e Sociedade (GEFSS/CNPq) e desenvolve pesquisas sobre mulheres no esporte, gênero nas atividades físico-desportivas e EF escolar, já a Profa. Dra. Silvana Goellner é coordenadora do Grupo de Estudos sobre Esporte, Cultura e História (GRECCO/CNPq) e desenvolve pesquisas sobre os seguintes temas: corpo, gênero, história do corpo e da EF, futebol e mulheres (CNPQ, 2019), sendo que, atualmente, se dedica ao Futebol de Mulheres.

Trata-se, portanto, a nosso ver, da construção de um conhecimento pautado na produção coletiva que se institui por meio dos grupos de pesquisa e, igualmente, esses dados reforçam a necessidade de mais PPGs da EF incorporarem docentes e discentes que se dedicam, seriamente, aos Estudos de Gênero e Interseccionais. 


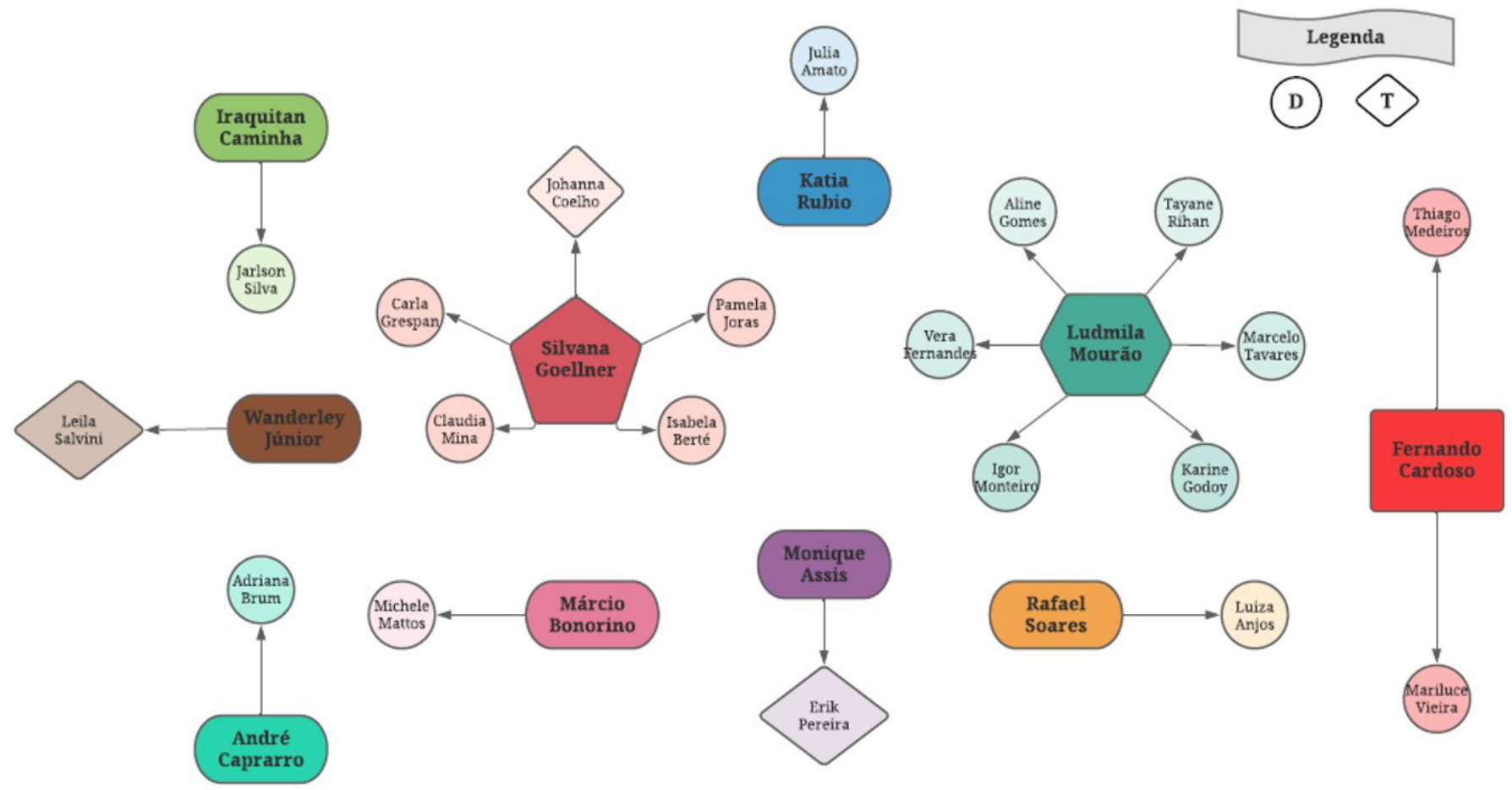

Figura 1. Relação entre orientadore e orientandes. Fonte: elaboração própria (2020).

Destacamos que as trajetórias dessas pesquisadoras foram sendo constituídas também pela temática em tela.

A fim de melhor compreender a relação entre orientadores e orientandes buscamos identificar quais as linhas de pesquisa iles integraram, uma vez que essa informação poderá contribuir para compreendermos as mediações teórico-metodológicas das pesquisas analisadas. Identificamos nos dados apresentados abaixo (Gráfico 3) que as linhas de pesquisa Esporte e suas manifestações e Representações sociais do movimento humano são os grandes lócus em que se encontram as pesquisas desenvolvidas entre os anos considerados em nossa pesquisa.

Ao sistematizarmos as informações até aqui apresentadas, pudemos identificar a importância que assumem os PPGs; as linhas de pesquisa desses programas; orientadores e os grupos de pesquisa. Sem essas instituições e agentes não haveria possibilidade de a temática de gênero adentrar o universo acadêmico da EF. Além disso é possível visualizar que algumas das carreiras docentes apresentam trajetórias muito bem delimitadas, fortalecidas pelos grupos e pelos PPGs, sendo essas articulações basilares para esses conhecimentos sejam pautados na EF.

\section{PROTAGONISTES E AS PESQUISAS SOBRE GÊNERO NA EF BRASILEIRA}

O segundo ponto que desenvolvemos diz respeito às protagonistes das dissertações e teses analisadas e, também, a um olhar aprofundado sobre o que essas pesquisas tematizam. 0 Gráfico 4 nos possibilita

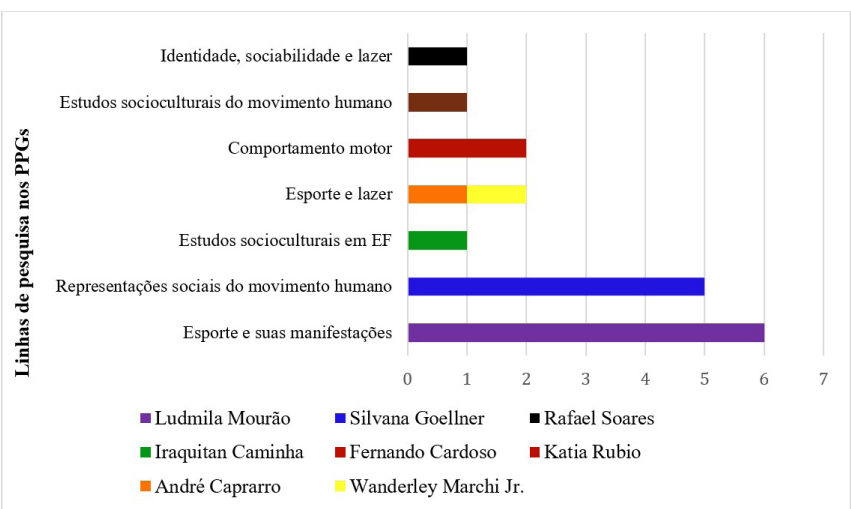

Gráfico 3. Vínculo de orientadore às linhas de pesquisa nos PPGs. Fonte: elaboração própria (2020).

visualizarmos como ocorreu a distribuição das produções no decorrer do período avaliado.

Podemos notar que o ano de 2016 é o mais expressivo quanto ao número de dissertações defendidas, um total de 6 pesquisas. Na passagem de 2014 para 2015 o total dissertações é idêntico, sendo que, no intervalo de um ano, 8 pesquisas foram desenvolvidas. Os anos de 2013, 2017 e 2018 revelaram uma significativa diminuição nas produções, dissertação ou tese, que envolvessem os Estudos de Gênero, o que possivelmente pode ser um efeito sintomático da ascensão de discursos radicais contra estes estudos. O Proyecto Género y Política en América Latina, desenvolvido pelo Observatorio de Sexualidad y Política (SPW), traçou o percurso de determinados movimentos intitulados conservadores 


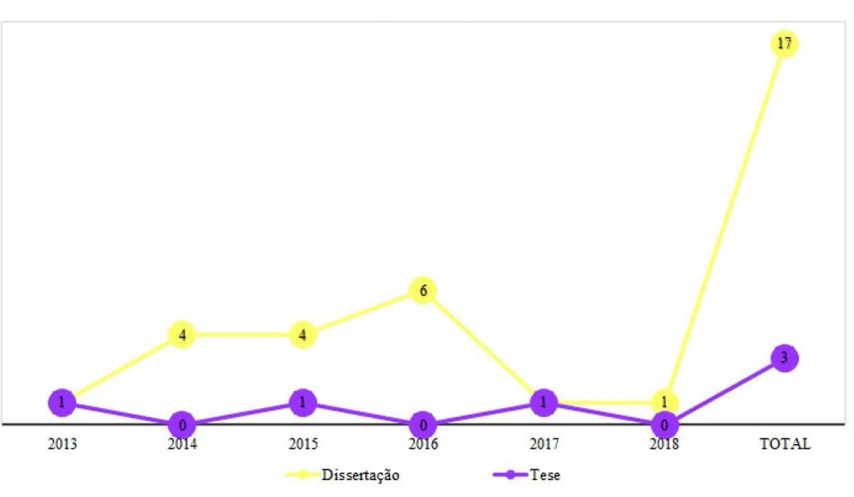

Gráfico 4. Tendência anual das pesquisas sobre gênero com base no tipo de produção. Fonte: elaboração própria (2020).

(retrógrados) até chegar ao momento da intensificação das ofensivas antigênero no contexto da América Latina e dataram a sua efervescência no ano de 2013.

Segundo relatório do projeto GPAL (2018) desde o início do século XX essas cruzadas eram gestadas por diversos grupos de pessoas e por instituições católicas como uma "resposta a mudanças muito profundas nos modos de perceber e viver a sexualidade, o gênero e a reprodução", sendo que o auge das investidas se deu a partir do fim da primeira década do século XXI ${ }^{4}$. Somado a isso, é possível que encontremos as justificativas da descontinuidade destas produções relacionadas a outros elementos, por exemplo, interesses particulares de cada pesquisadore e mudanças de foco quanto aos objetos/ sujeitos de pesquisa.

O próprio campo científico da EF possui critérios de avaliação que não estão atentos as especificidades das pesquisas fundamentadas pelas Ciências humanas e sociais, e que são (quase) unanimidade entre as produções aqui analisadas (Silveira, 2016). Verificamos que $90 \%$ da amostra foi elaborada a partir de abordagens metodológicas qualitativas com aportes teóricos oriundos da Sociologia. Apenas as dissertações de Thiago Medeiros e Mariluce Vieira, orientades por Fernando Cardoso, PPGCMH/SC, empregaram protocolos da Psicologia Cognitiva para aferirem "Esquemas de Gênero do Autoconceito" ${ }^{5}$ entre participantes das pesquisas.

No caso das teses, os anos de defesa corresponderam respectivamente à 2013, 2015 e 2017, sendo que em cada ano 1 pesquisa foi concluída. Especificamente em 2015, a tese é apresentada em estilo escandinavo. É importante salientarmos que nem todos os PPGs da EF dispõem de doutorado acadêmico ou profissional. Soares (2018, p. 290) aponta que, nacionalmente, "o número de programas de doutorado, nas diversas áreas do conhecimento, duplicou entre 2000 e 2010", em

4 Género y Política en América Latina. Disponível em: https:// sxpolitics.org/GPAL/. Acesso em: 14 novembro 2019.

5 GIAVONI, A.; TAMAYO, A. Inventário dos Esquemas de Gênero do Autoconceito. Psicologia: Teoria e Pesquisa, 16, 175-184, 2000.
10 anos o número de doutores formades passou de 4.000 para aproximadamente 15.000 e o de mestres saltou de 20.000 para aproximadamente 40.000 , sendo que diles, apenas um terço avançou para o doutorado.

Em relação a autoria das pesquisas analisadas, há uma preponderância de mulheres. Isso foi verificado ao longo de todo o período e constatamos que em alguns anos, 2013; 2017; e; 2018, as dissertações ou teses foram frutos apenas do protagonismo delas, como evidenciado no Gráfico 5. Também é possível observar que, no período de seis anos, um total de 15 mulheres e 5 homens fundamentaram suas produções nos conhecimentos sobre gênero. Neste ponto, amparades pelas reflexões de Preciado (2018, p. 127) esclarecemos ter consciência de que fixamos os resultados a seguir considerando o "regime sexopolítico" do ocidente (Preciado, 2018, p. 129), embora

a certeza de ser homem ou mulher seja uma bioficção somatopolítica produzida por um conjunto de tecnologias do corpo, técnicas farmacológicas e audiovisuais que determinam e definem o alcance das nossas potencialidades somáticas e funcionam como próteses de subjetivação (Preciado, 2018, p. 127).

As Estatísticas de Gênero: indicadores sociais das mulheres no Brasil, divulgadas pelo IBGE (2018, p. 7) apontam que "as mulheres atingem um nível de qualificação no Ensino Superior que é maior que o dos homens", entretanto, grandes obstáculos ainda precisam ser superados para que possamos falar em acesso, permanência e em acréscimos de titulações quando o foco são as IES. Segundo consta no documento, "há uma considerável desigualdade entre mulheres brancas e mulheres pretas ou pardas, a qual evidencia que a cor ou a raça é um fator preponderante na desigualdade educacional, mesmo entre as mulheres que mais se beneficiaram da crescente escolarização".

Como consequência da leitura integral das dissertações e teses, avançamos na análise dos temas abordados e identificamos que as pesquisas protagonizadas por mulheres apresentaram centralidade na temática mulheres. Ademais, o restante das produções tematizou: papeis sexuais; identidades; sexualidade $e$ estereótipos ${ }^{6}$. Vejamos no Gráfico 67:

6 Estabelecemos como critério focalizar os capítulos e trechos textuais que apresentassem maior densidade e aprofundamento nas discussões sobre gênero para realizar essa categorização, a qual foi feita com o uso do software IRAMUTEQ.

7 A partir deste gráfico duas pesquisas foram excluídas das análises, uma vez que estruturadas em estilo escandinavo, o que foi um impedimento para que as enquadrássemos em uma categoria temática e fosse viável submetê-las às análises do IRAMUTEQ. São elas: (dissertação) Aulas mistas na EF: tensões e contradições de Michele Z. de Mattos sob a orientação de Márcio Bonorino; e (tese) Relações de gênero na imprensa esportiva de Erik Giuseppe B. Pereira sob a orientação de Monique R. de Assis. 


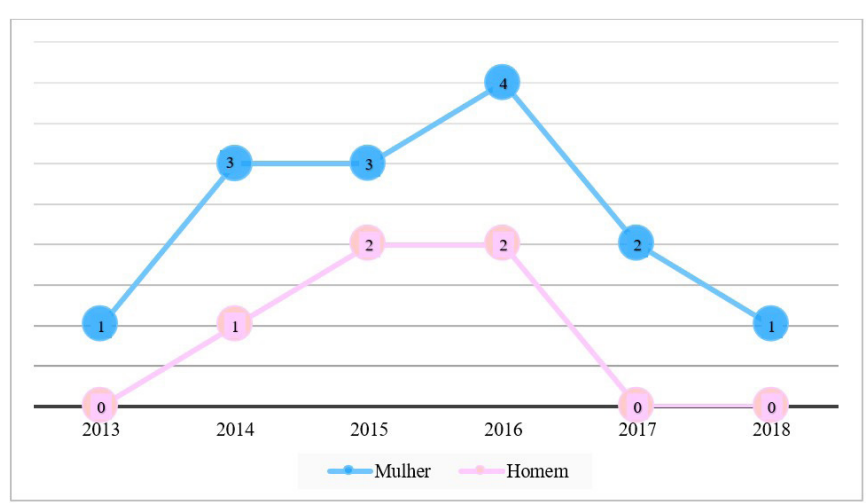

Gráfico 5. O sexo des pesquisadores considerando o ano em que ocorreu a conclusão da dissertação ou tese. Fonte: elaboração própria (2020).

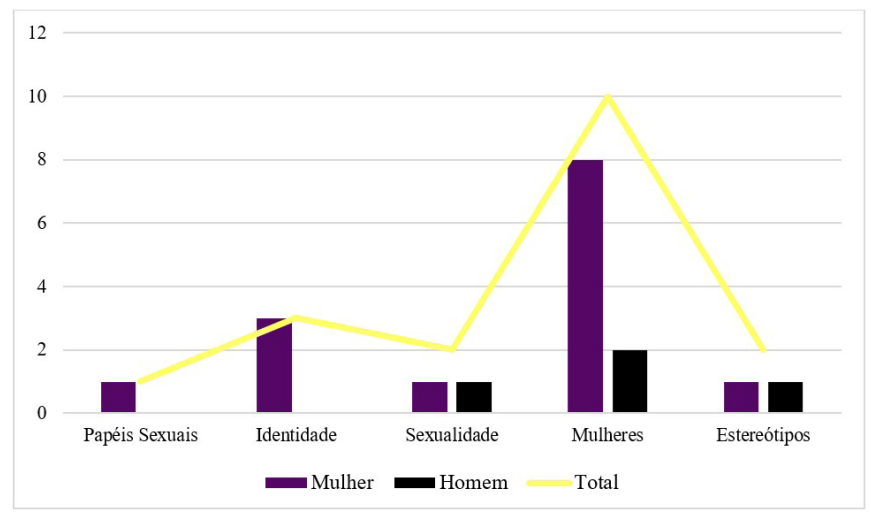

Gráfico 6. Totalidade das produções segundo o sexo des pesquisadores e a categoria temática das pesquisas. Fonte: elaboração própria (2020).

Conforme se observa, de um total de 18 pesquisas, 8 foram dedicadas d'elas para elas, mediante à escrita das histórias de mulheres atletas; da apresentação de um processo de construção do habitus esportivo; e/ou da denúncia de opressões e desigualdades vivenciadas nos contextos da EF. Já as categorias temáticas em que são verificadas produções desenvolvidas por homens são: estereótipos; sexualidade; e mulheres. Papéis sexuais e identidade figuram entre as categorias em que apenas mulheres desenvolveram pesquisas. A linha amarela indicando o total de produções pode ser lida a partir do somatório entre as pesquisas realizadas pelas mulheres e as realizadas pelos homens.

Quanto à distribuição das categorias temáticas de acordo com o ano de defesa, é possível observar que há uma tendência de as produções apresentarem um crescimento nos anos de 2014, 2015, sendo que o pico é em 2016, períodos em que mulheres foi a categoria temática em voga (ver Gráfico 7).

Ao refletirmos sobre o contexto esportivo brasileiro, constatamos que estes foram os anos de ocorrência de dois megaeventos, a Copa do Mundo FIFA 2014, futebol de homens, e os Jogos Olímpicos Rio 2016, ambos

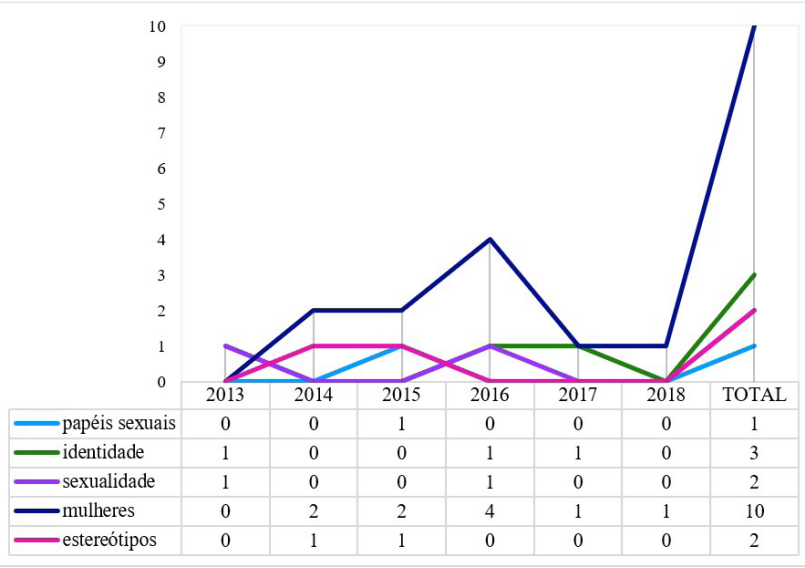

Gráfico 7. Total de pesquisas desenvolvidas com base nas categorias temáticas e ano de defesa. Fonte: elaboração própria (2020).

sediados no Brasil. Parece oportuno destacar que no quesito desigualdade de gênero, raça e classe, ambos eventos são campeões. A título de exemplo, apontamos as discrepâncias salariais existente entre jogadoras e jogadores, uma vez que a FIFA direciona à Copa do Mundo de futebol de mulheres quase dez vezes menos do que o prêmio final oferecido aos homens, cujas equipes são compostas por atletas com remunerações muitíssimo discrepantes.

Lamentavelmente, os baixos salários não estão restritos ao universo esportivo, segundo o World Economic Forum (2018), "as mulheres recebem em média 38\% menos que os homens para desempenhar a mesma função" e esta situação se agrava em períodos de recessão e crises, quando as mulheres, sobretudo as negras, são as primeiras a perderem os empregos, conforme exposto pela professora Márcia Lima (Estadão, 2019), do departamento de Sociologia da USP, em entrevista ao jornal Estadão 8 .

Em relação ao que denominamos como contextos pesquisados, os quais expressam os cenários da EF que figuraram nas produções, constatamos três lócus distintos: esportivo, escolar e lutas; conforme expresso no Gráfico 8:

É interessante observar que apesar do contexto esportivo se destacar em relação aos demais, no ano de 2014 as lutas representaram um lócus de investigação em evidência. Neste caso, é possível que em 2012, dois anos antes, os objetos já estivessem a ser delineados, a julgar pela "importância que a mídia esportiva deu para incorporação das mulheres pelo Ultimate Fighter Championship (UFC), a partir do anúncio da contratação

8 Matéria: Desigualdade salarial cresce no Brasil e mulheres são as primeiras a sentir impacto da crise. Disponível em: https://arte.estadao.com.br/focas/capitu/materia/ mulheres-sao-as-primeiras-a-sentir-impacto-da-criseenquanto-desigualdade-salarial-cresce-no-brasil. Acesso em: 14 novembro 2020. 


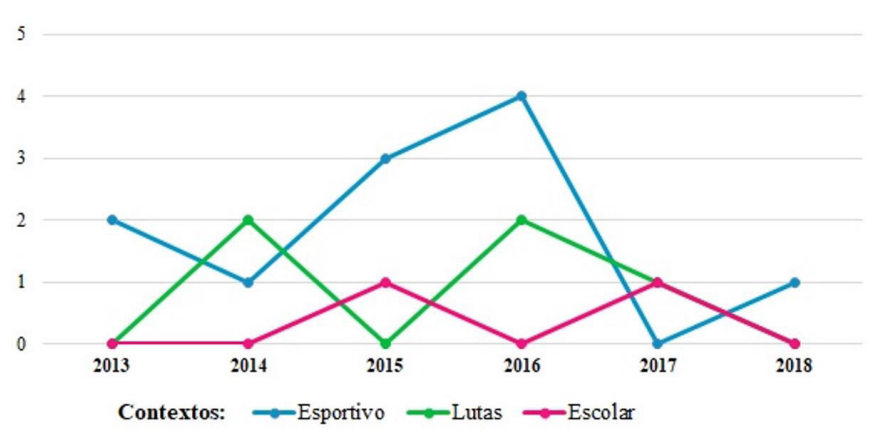

Gráfico 8. Tendência produtiva com base nos contextos pesquisados e ano de defesa. Fonte: elaboração própria (2020).

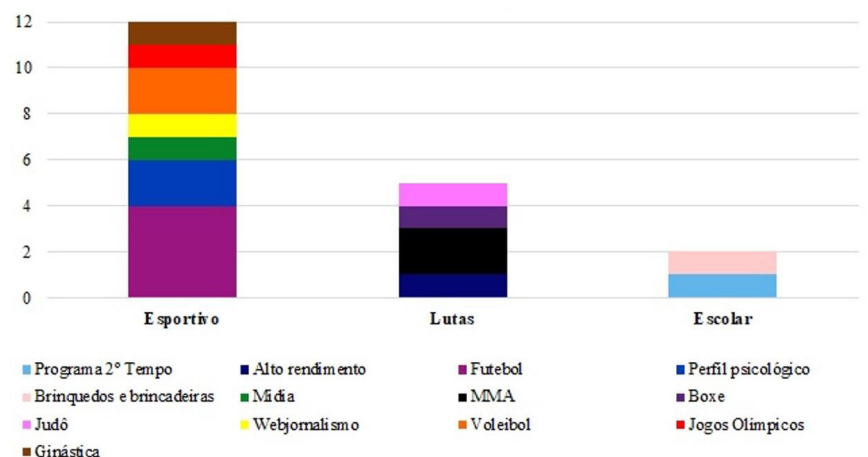

Gráfico 9. Objetos de pesquisa das dissertações e teses considerando-se os contextos pesquisados. Fonte: elaboração própria (2020).

de Ronda Rousey" (Grespan, 2014), e posteriormente, com a divulgação e exibição dos combates entre mulheres.

Quanto ao contexto esportivo os anos ápices para as pesquisas foram 2015 e 2016, totalizando 7 produções. Já o contexto escolar foi representado em 2 pesquisas desenvolvidas entre os anos de 2015 e 2017. Ademais, seguem as especificidades estabelecidas peles pesquisadores em relação a cada um dos cenários (Gráfico 9) ${ }^{9}$.

Em relação ao contexto esportivo o foco das pesquisas foram principalmente o futebol e a mídia esportiva/webjornalismo, acompanhados de voleibol e perfis psicológicos de atletas. No contexto das lutas, houve uma similaridade no tratamento de todas as especificidades, porquanto, 2 pesquisadoras dedicaram-se a focar no MMA. Entre as pesquisas

9 O Gráfico 9 é expresso respectivamente pelas cores das bandeiras: LGBTQIAP+ Racial, faltando apenas a cor preta para que a representação se completasse; Gênero fluido; e Trans. Todas as cores presentes nos gráficos deste artigo foram escolhidas a fim de que pudéssemos dar visibilidade às diversidades e questões inerentes do universo LGBTQIAP+. Disponível em: https://diversitybbox.com/pt/ bandeiras/. Acesso em 15 set. 2020. desenvolvidas no contexto escolar as ênfases foram o Programa Segundo Tempo e; brinquedos e brincadeiras, ambas pensando os processos pelos quais a educação e as vivências entre meninas e meninos possam ser repensadas/transformadas a ponto de gerarem igualdade de fato.

Em síntese, é possível identificar que o maior protagonismo entre as pesquisas analisadas é das mulheres. Considerando os contextos esportivo, escolar e lutas. $O$ tema mais investigado e que atravessa os Estudos de Gênero é a categoria mulheres. Elas assumem, portanto, a responsabilidade de percorrer por epistemologias ocasionalmente rejeitadas no campo científico da $\mathrm{EF}$, dando visibilidade às pessoas invisíveis no universo de práticas que ainda são legitimadas por homens e para homens, assim como lançam luz sobre estudos que têm origem nas lutas por direitos civis, empreendidas pelos movimentos feministas, negros e LGBTQIAP+.

\section{CONCLUSÕES}

Após a exposição e análise das informações apresentadas, destacamos que as dissertações e teses investigadas, refletem as demandas políticas e sociais que se apresentam quanto à categoria gênero. A despeito das dificuldades e hostilidades que suportamos por nos debruçarmos sobre determinados temas de pesquisa, é possível afirmar que cada vez mais temos avançado, mas necessitamos expandir nossas discussões, torná-las presentes e pertinentes de serem protagonizadas por outres pesquisadores em PPGs da EF de outras regiões e estados do Brasil, assim, descentralizar a supremacia de sul-sudeste, logicamente, sem desconsiderar as grandes contribuições das pesquisas e grupos estabelecidos nestas regiões.

Embora este artigo não se proponha a centrar-se no julgamento da qualidade das produções analisadas e apresente um caráter eminentemente descritivo, reforçamos que o detalhamento acerca das pesquisas sobre gênero "deve ser entendido apenas como um recurso instrumental" (Bracht et al., 2012, p. 29), não significando que os conhecimentos elaborados seguem ou podem ser definidos, exclusivamente, pelas categorias temáticas aqui propostas e informações que apresentamos. Ao sistematizar esta pesquisa cogitamos que ela ajudaria a situar novos debates e a estimular outras/novas ideias para que não nos mantenhamos preses a "estereotipias que exercem um poder simplificador sobre o que pretendemos elucidar" (Bracht et al., 2012, p. 29).

A mensuração das dissertações e teses sobre gênero, concebidas por membros da comunidade científica da EF, não constitui fim em si mesma, referindo-se, sim, a uma tentativa de apresentar a dinamicidade do processo de construção e distribuição de conhecimentos. Além disso, mostra a importância de termos instituições e agentes que se incumbem por garantir espaços para a 
realização dessas pesquisas acolhendo pesquisadores dessa temática. Que possamos ampliar essa trajetória. Sigamos.

\section{FINANCIAMENTO}

Trabalho fruto da dissertação de Mestrado Gênero na Educação Física brasileira: aspectos da produção científica a partir das teses e dissertações (2013 - 2018) de autoria de Jéssica de Moura Pereira e realizado com o apoio da Coordenação de Aperfeiçoamento de Pessoal de Nível Superior - Brasil (CAPES) - Código de Financiamento 001. Edital no 05/2018 do PPGEF/UnB. № da bolsa: 88882.384197/2019-1.

\section{CONFLITO DE INTERESSES}

As autoras declaram não haver conflitos de interesse.

\section{REFERÊNCIAS}

Bauer MW, Gaskell G. Pesquisa qualitativa com texto, imagem e som: um manual prático. 7. ed. Petrópolis, RJ: Vozes; 2008.

Booth D. Olympic city bidding: an exegesis of power. London: International Review for the Sociology of Sport; 2011.

Bracht V, Faria B, Moraes C, Fernandes, ES, Almeida, FQ, Ghidetti, FF, et al. A EF Escolar como tema da produção do conhecimento nos periódicos da área no Brasil (19802010): parte II. Movimento 2012;18(2):11-37.

CNPQ: Conselho Nacional de Desenvolvimento Científico e Tecnológico [internet]. Diretório dos grupos de pesquisa do Brasil. Brasília: CNPq; 2019 [citado em 2019 Nov 14]. Disponível em: http://lattes.cnpq.br/web/dgp/home

Estadão [Internet]. Desigualdade salarial cresce no Brasil e mulheres são as primeiras a sentir impacto da crise. São Paulo: Editora Capitu; 2019 [citado em 2020 Nov 14]. Disponível em: https://arte.estadao.com.br/focas/capitu/ materia/mulheres-sao-as-primeiras-a-sentir-impacto-dacrise-enquanto-desigualdade-salarial-cresce-no-brasil.

Dunning E, Maguire J. As relações entre os sexos no esporte. Estud Fem 1997;5(2):321-48.

GPAL: Género y Política en América Latina [internet]. Rio de Janeiro: GPAL; 2018 [citado em 2019 Nov 14]. Disponível em: https://sxpolitics.org/GPAL/
Grespan, C. Mulheres no octógono: performatividades de corpos e de sexualidades [dissertação]. Porto Alegre: Escola de Educação Física, Universidade Federal do Rio Grande do Sul; 2014.

Haraway D. Saberes localizados: a questão da ciência para o feminismo e o privilégio da perspectiva parcial. Cadernos Pagu 1995;(5):07-41.

Hirata H, Laborie F, Doaré H, Senotier, D. Dicionário Crítico do Feminismo. São Paulo: Editora UNESP; 2009.

IBGE: Instituto Brasileiro de Geografia e Estatística [internet]. Estatísticas de Gênero: indicadores sociais das mulheres no Brasil. Brasilia: IBGE; 2018. [citado em 2019 Nov 14]. Disponível em: https://educa.ibge.gov.br/jovens/ materias-especiais/materias-especiais/20453-estatisticasde-genero-indicadores-sociais-das-mulheres-no-brasil. html\#subtitulo-1

Maricato JM, Noronha DP. Indicadores bibliométricos e cientométricos em CT\&I: apontamentos históricos, metodológicos e tendências de aplicação. In: Hayashi MCPI, Leta J, editores. Bibliometria e Cientometria: reflexões teóricas e interfaces. São Carlos: Pedro \& João; 2012.

Preciado, P. B. Testo Junkie: sexo, drogas e biopolítica na era da farmacopornografia. São Paulo: N-1 Edições; 2018.

Scavone L. Prefácio à Edição Brasileira. In: HIRATA H, LABORIE F, DOARÉ H, SENOTIER D, editores. Dicionário Crítico do Feminismo. São Paulo: Editora UNESP; 2009.

Sidone OJG, Haddad EA, Mena-Chalco JP. A ciência nas regiões brasileiras: evolução da produção e redes de colaboração científica. Campinas: TransInformação; 2016. p. 15-31.

Silveira R. Vivendo Ciências: as (co)existências de diferentes ontologias científicas da EF [Tese]. Porto Alegre: Escola de Educação Física, Universidade Federal do Rio Grande do Sul; 2016.

Soares PC. Contradições na pesquisa e Pós-graduação no Brasil. São Paulo: Estudos Avançados; 2018. p. 289-313.

Vaitsman J. Hierarquias de Gênero e Iniquidade em Saúde. Revista de Saúde Coletiva (PHYSIS) 1994;4(1):7-22.

WORLD ECONOMIC FORUM. The Global Gender Gap Report 2018. Edition: World Economic Forum, 2018. ISBN-13: 978-2-940631-00-1. 


\section{ERRATA: Análise da produção científica sobre gênero na Educação Física brasileira entre os anos de 2013 e 2018: uma perspectiva Cientométrica}

Jéssica de Moura Pereiraa ${ }^{a}$ Dulce Maria Filgueira de Almeidab ${ }^{\text {, Raquel da Silveirac }}$

aUniversidade Estadual de Goiás, Escola Superior de Educação Física e Fisioterapia de Goiás. Goiânia, GO, Brasil.

bUniversidade de Brasília, Faculdade de Educação Física, Programa de Pós-graduação em Educação Física, Núcleo de Estudos do Corpo e Natureza. Brasília, DF, Brasil.

'Universidade Federal do Rio Grande do Sul, Programa de Pós-graduação em Ciências do Movimento Humano da Escola Superior de Educação Física. Porto Alegre, RS, Brasil.

Por conta de erro honesto das autoras, o artigo "Análise da produção científica sobre gênero na Educação Física brasileira entre os anos de 2013 e 2018: uma perspectiva Cientométrica", com número de DOI: https:// doi.org/10.1590/rbce.43.e006921, foi publicado na Revista Brasileira de Ciência do Esporte, 2021; 43: e006921, com erros.

No resumo, onde se lia:

“PPGEF/UFMG e PPGCMH/UFRGS"

Leia-se:

“PPGEF/UFJF-UFV e PPGCMH/UFRGS”

No abstract, onde se lia:

"PPGEF/UFMG and PPGCMH/UFRGS"

Leia-se:

"PPGEF/UFJF-UFV and PPGCMH/UFRGS"

No resumen, onde se lia:

"PPGEF/UFMG y PPGCMH/UFRGS"

Leia-se:

“PPGEF/UFJF-UFV y PPGCMH/UFRGS"

Na página 4, onde se lia:

"Verifica-se que há uma preponderância na orientação das dissertações e teses por parte das professoras Ludmila Mourão (PPGEF/MG) e Silvana Goellner (PPGCMH/RS)".

Leia-se:

"Verifica-se que há uma preponderância na orientação das dissertações e teses por parte das professoras Ludmila Mourão (PPG/MG) e Silvana Goellner (PPG/RS)".

As autoras pedem desculpas pelas falhas. 